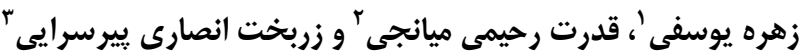

(- دانش أموخته كارشناسى ارشد گروه علوم دامى، دانشخاه علوم كشاورزى و منابع طبيعى سارى، (نويسنده مسوول: yosefi_2004@yahoo.com)

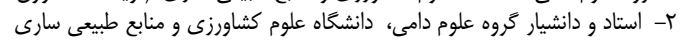
تاريخ دريافت: 9F/F/II

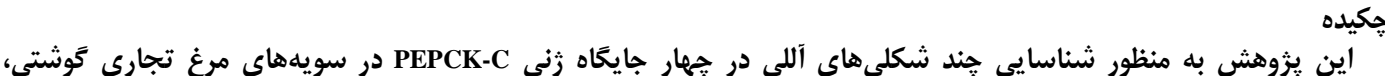

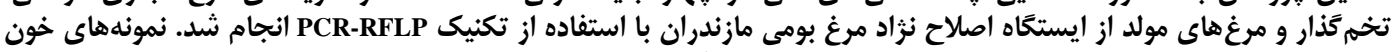

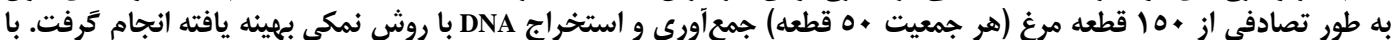

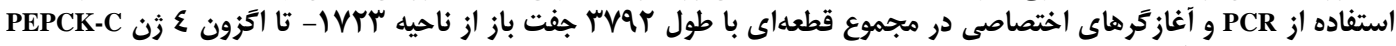

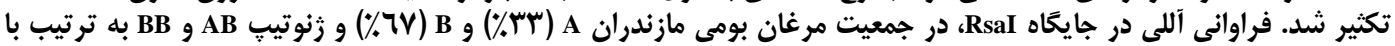

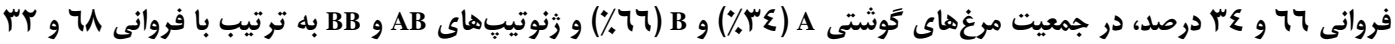

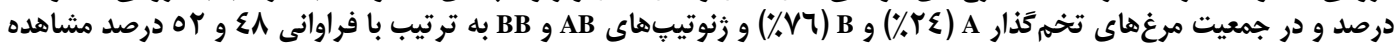

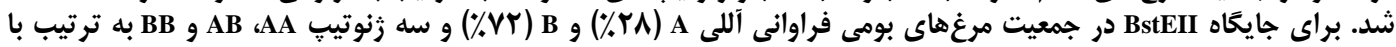

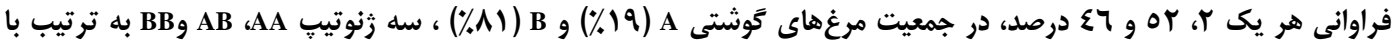

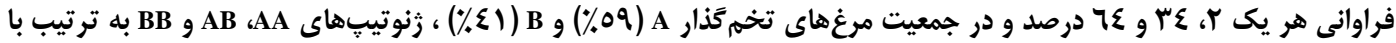

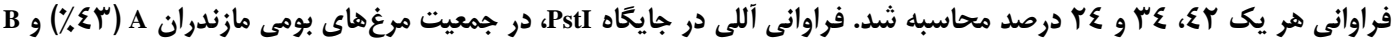

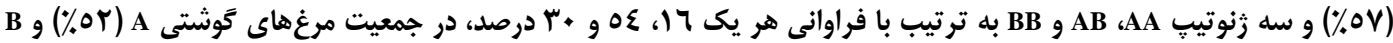

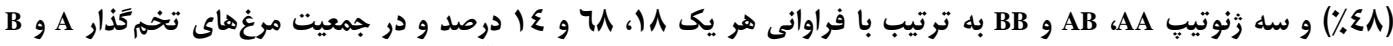

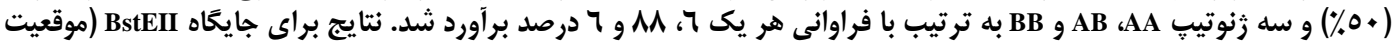

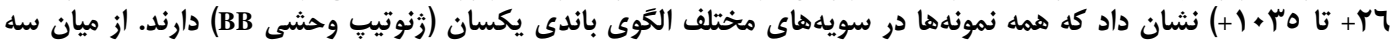

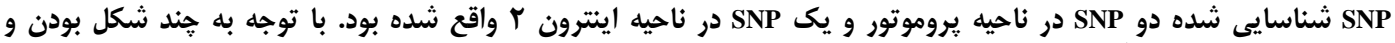

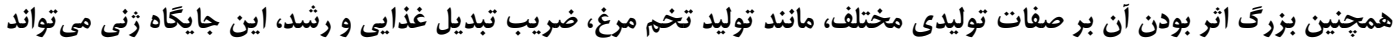

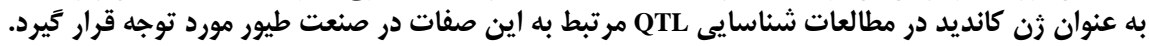

وازههاى كليدى: جند شكلى، PEPCK-C، مرغ، PCR-RFLP

ايزوفرم PEPCK (فرمهاى سيتوزولى و ميتوكندريايى) با

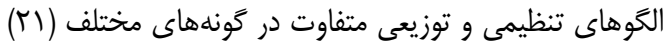

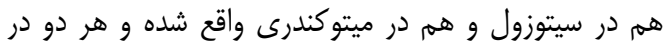

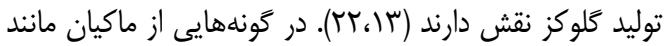

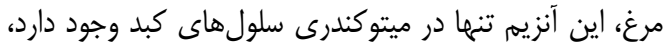

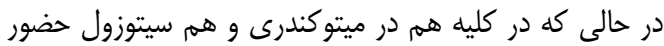

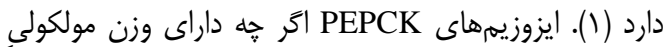

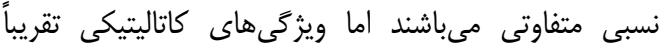

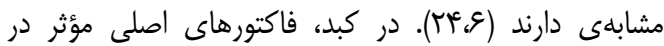

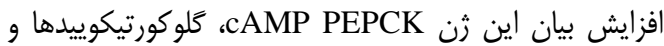

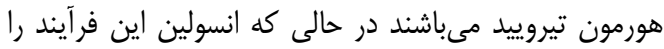

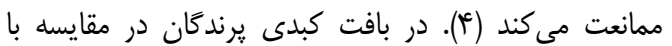

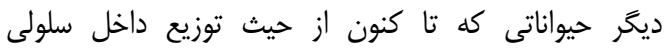
PEPCK

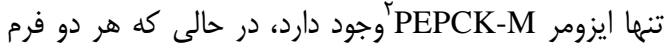

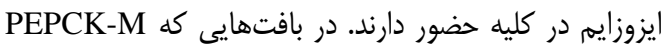

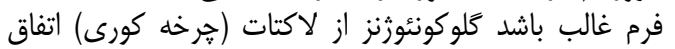

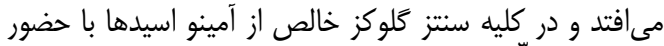
PEPCK-C

1- Phosphoenolpyruvate Carboxykinase

3- Cytosolic Phosphoenolpyruvate Carboxykinase
مقدمه

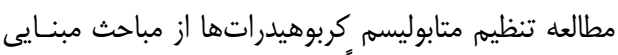

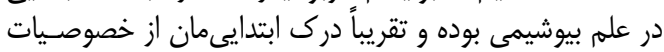

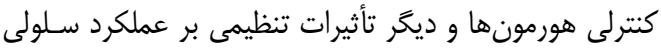

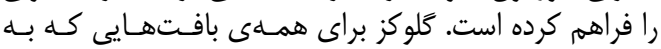

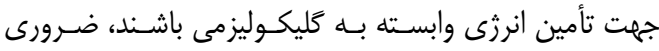

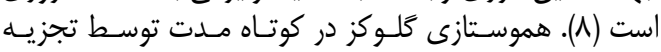

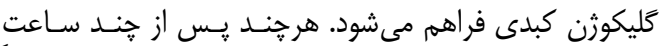

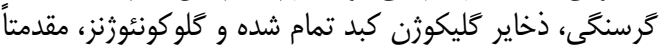

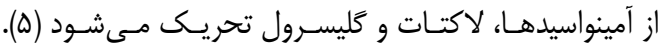

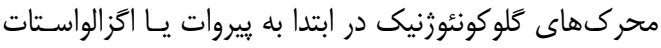

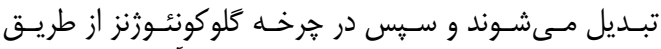

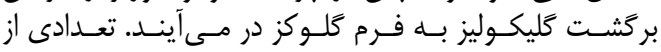

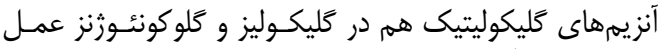

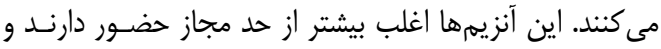

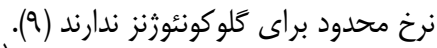

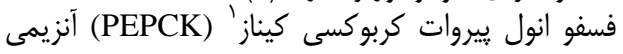

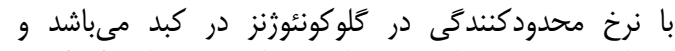

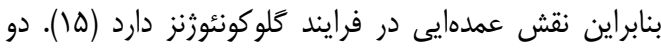

2- Mitochondrial Phosphoenolpyruvate Carboxykinase 
وجود دارند كه در اكثر آزمايشات اين آللها (كلاسهاى هايلوتايت)، توسط روش

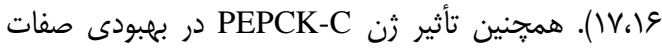
توليدى طيور نظير ضريب تبديل غيدين غذائى و مقدار تخمرمرغ

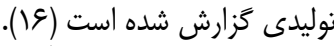

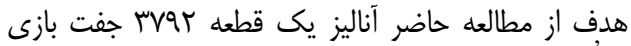

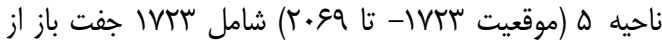

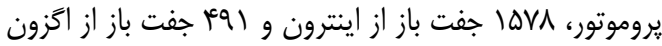

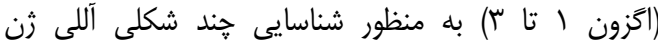
PEPCK-C

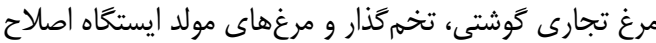

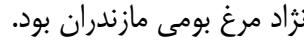

\section{مواد و روشها - ماد جمع آورى نمونه}

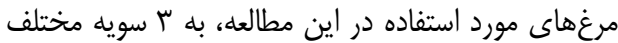

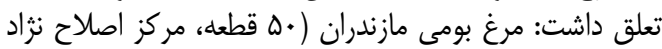

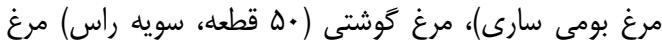

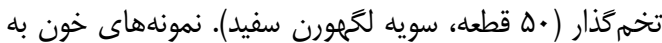

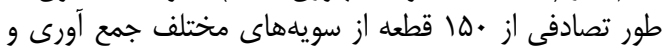

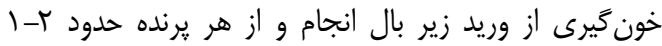

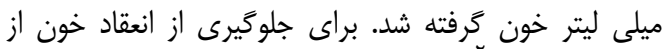

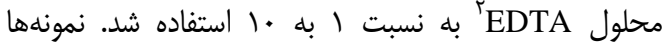

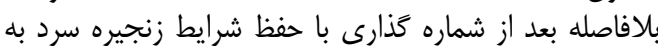

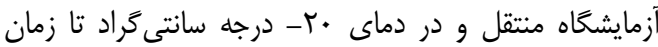

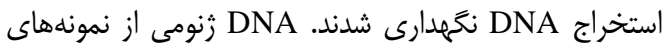

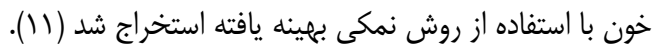

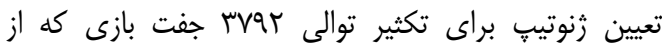

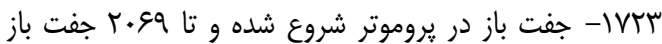

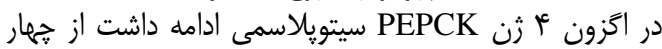

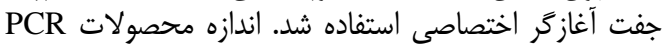

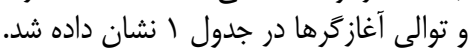

فرضيه حمايت كرد كه كليه در مرغ، مكان اصلى كلوكونئوزنز

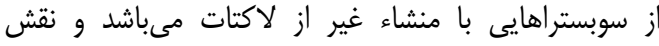

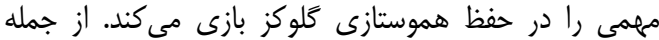

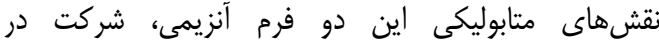

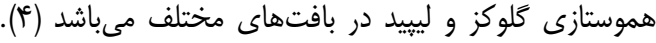

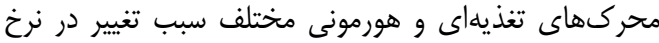

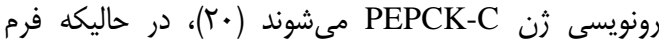

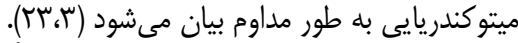

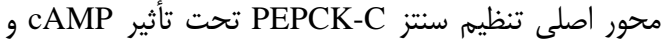

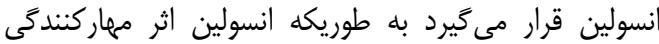

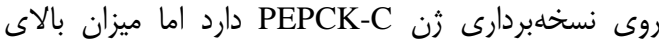
كربوهيدرات جيره از طريق افرئ افزيش ترشح انسولين باعث

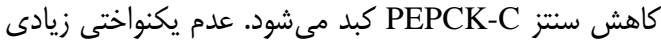

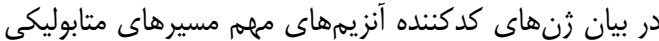

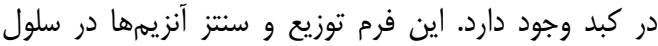

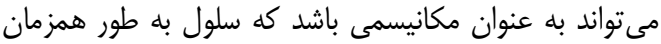

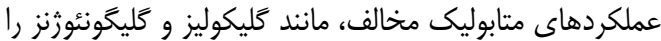

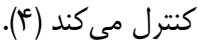
ثن PEPCK-C در طيور با طولى معادل ^ ميلو باز

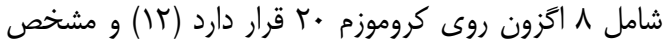

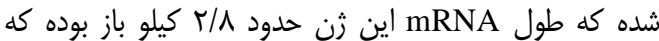
يروتئينى به طول rاه

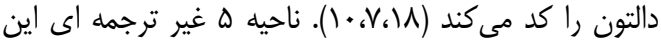

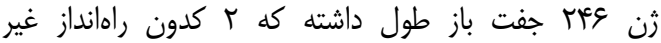

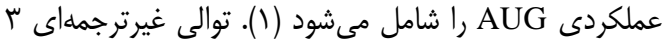

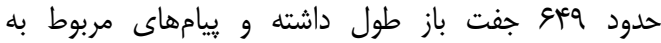

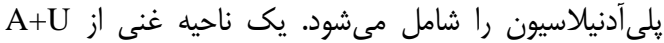

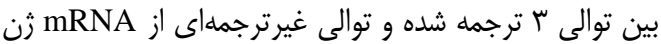

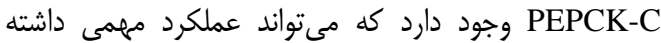

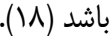

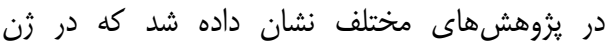
جند شكلى وجود دارد و آللهاى متفاوتى از از اين ثن ثن

جلدول ا- توالى آغازگرها و موقعيت ناحيه تكثيرى ثن PEPCK-C Table 1. The primer sequences and the position of amplified region of PEPCK-C gene

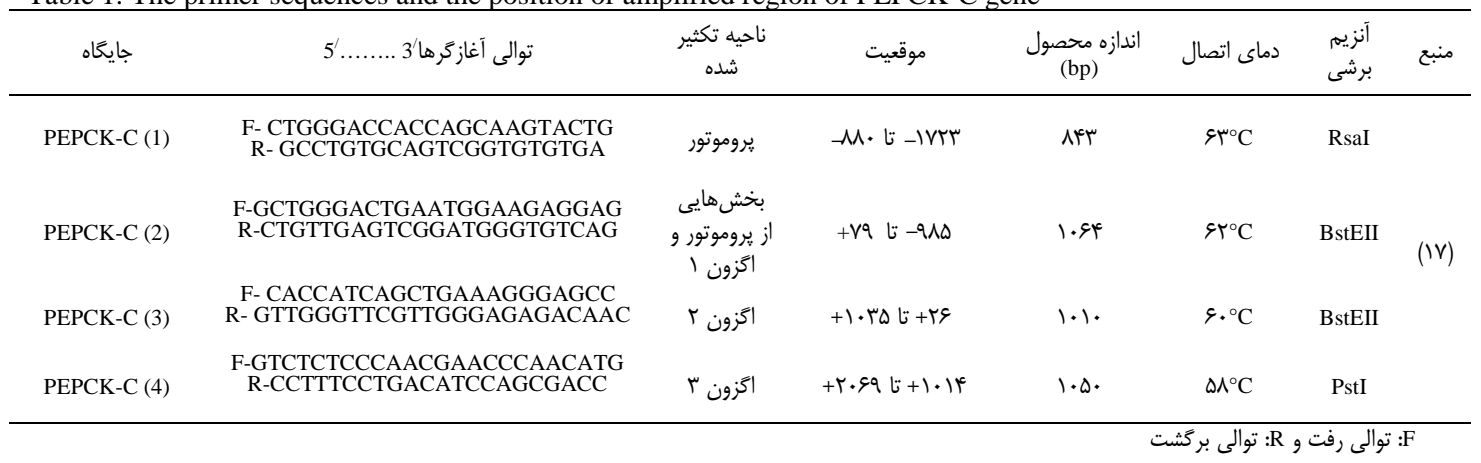

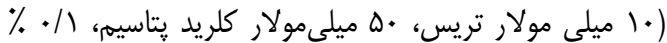

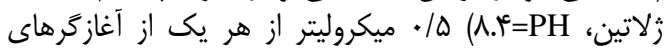

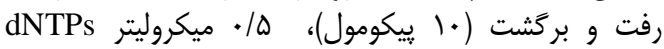

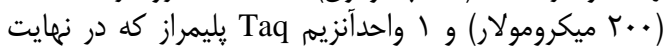

1- Restriction Fragment Length Polymorphism
واكنش زنجيرهاى يليمراز (PCR)

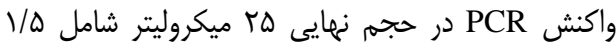

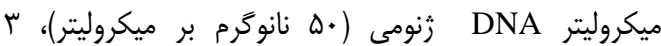

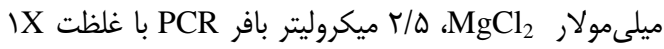


زنوتيڤها از روى زل محاسبه شد. مقايسه فراوانى زنى و

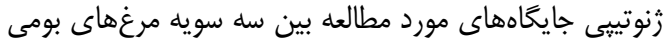

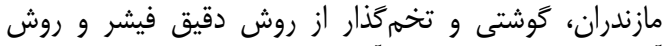

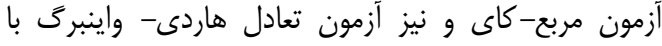

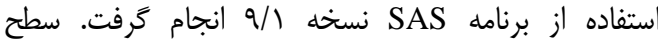

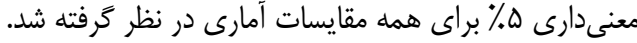

\section{نتايج و بحث

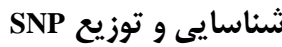
PEPCK-C (1) براي جايكاه RsaI- RFLP

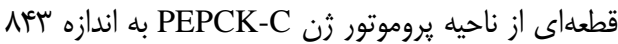

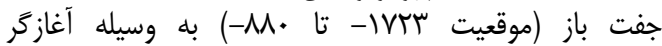

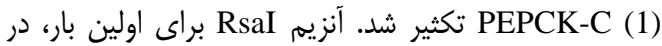

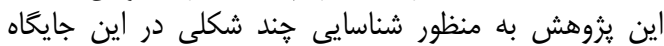

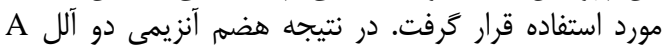

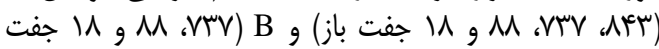

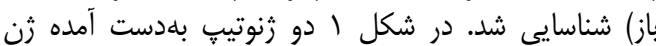

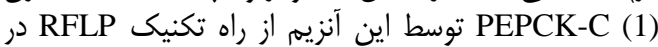
سه سويه مختلف مرغ نشان داده شد.

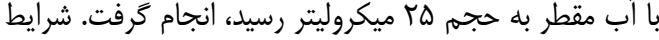

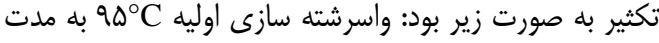

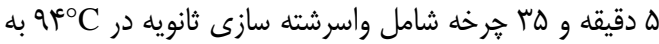

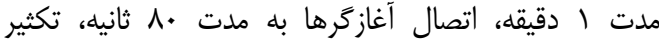

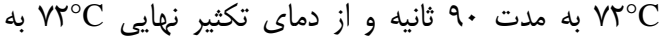

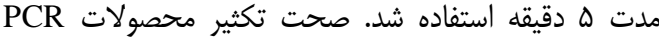

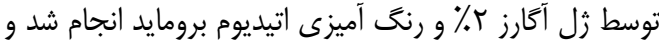
با استفاده از دستخاه مستندسازى زل زئ (بايورد، آمريكا) باندها رويت و مورد آزمون قرار كرفتينداه مستندساري آزمون PCR-RFP

جس از تكثير، محصولات PCR تحت تيمار آنزيم مربوطه

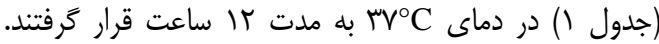

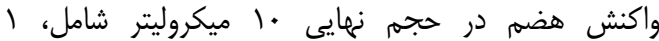

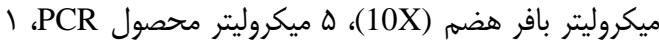

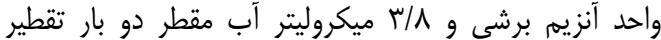

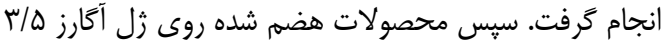

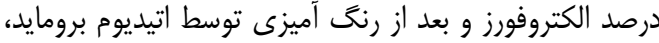
تعيين زنوتيٍ شدند. آناليز آمارى توني فراوانى زنى و زمارى زنوتييى با شمارش مستفيم آللها و

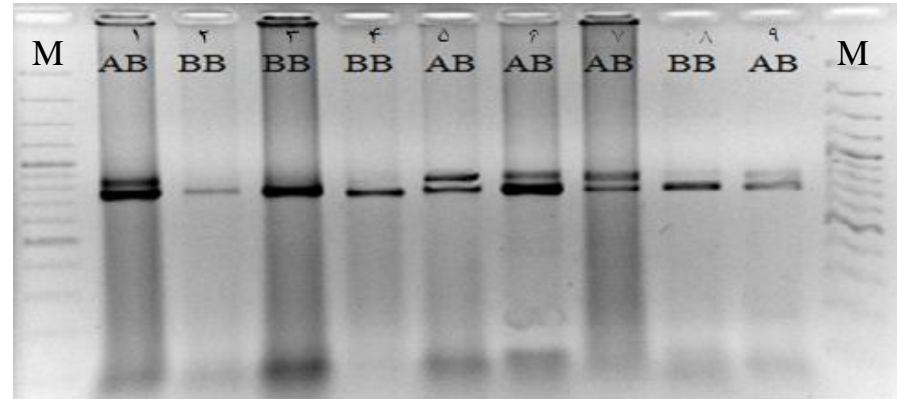

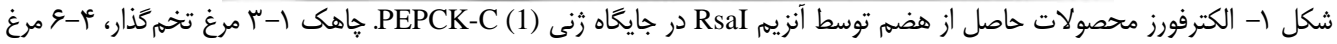

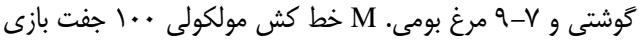

Figure 1. Electrophoresis of digestion products by RsaI enzyme in PEPCK-C (2) locus. Lane 1-3 layer, 4-6 broiler and 7-9 native fowls. $\mathrm{M}$ is the $100 \mathrm{bp}$ molecular ruler

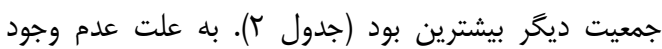

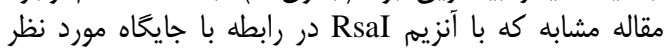

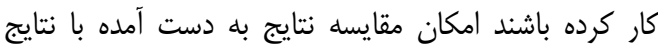
محققين ديخر ميسر نبوده است.
زنوتيب AA در هيج يك از جمعيتها مشاهده نشد كه

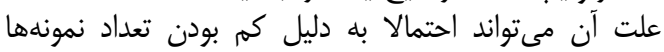

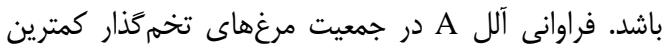

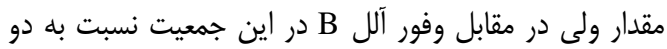

جدول r- فراوانى هاى آللى و زنوتيبى جايگاه زنى (1) PEPCK-C در سه سويه مختلف مرغ Table 2. The allelic and genotypic frequencies of PEPCK-C (1) locus in three different strains of chickens

\begin{tabular}{|c|c|c|c|c|c|c|c|}
\hline \multicolumn{3}{|c|}{ سطح احتمال (P-value) } & \multicolumn{2}{|c|}{ فراوانى آللى } & \multicolumn{2}{|c|}{ فراوانى رُنوتييى } & \multirow[b]{2}{*}{ جمعيت } \\
\hline مرغ تخمكذار & مرغ گوشتى & مرغ بومى & B & A & BB & $\mathrm{AB}$ & \\
\hline $.1 .991^{\mathrm{IS}}$ & $\cdot \mid \wedge)^{\prime} \mid \varepsilon^{n S}$ & ---- &.$/ 9 \mathrm{~V}$ & سז/. & $\cdot / M F$ & .199 & مرغ بومى \\
\hline $.1 \cdot$ ETA & ---- & . & .199 & EF & זr/. & .191 & مرغ گوشتى \\
\hline ----- & $.1 .+4 t \Lambda^{\circ}$ & $.1 .991^{\mathrm{ns}}$ & $\cdot / V 8$ &.$/ 4 F$ & . /DT & $\cdot / \uparrow \wedge$ & مرغ تخمثذار \\
\hline
\end{tabular}

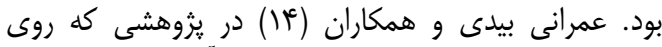

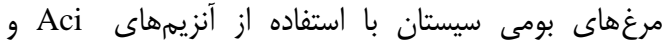

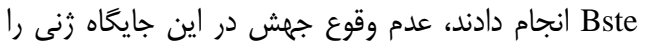

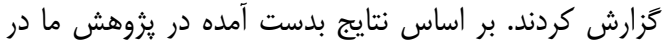

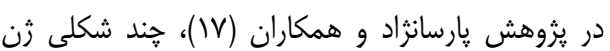
PEPCK-C

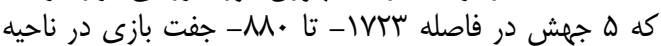

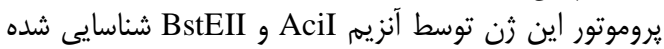




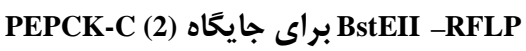

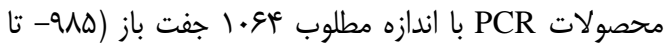

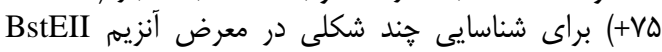

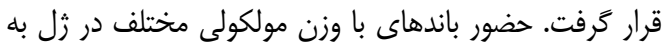

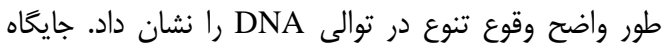

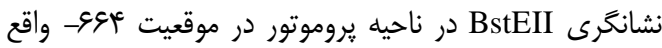

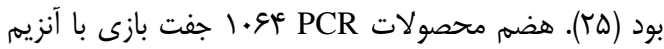

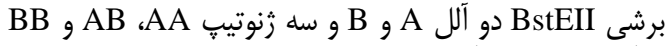

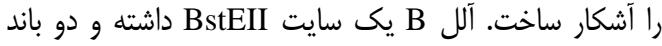

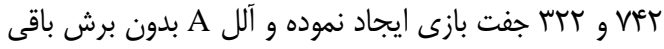

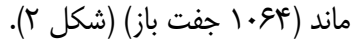

هيج كدام از سه جمعيت، زنوتيڤ هموزيخوت AA مشاهده

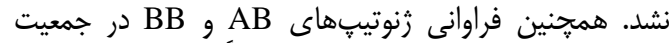

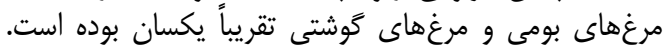

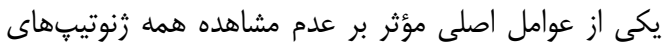

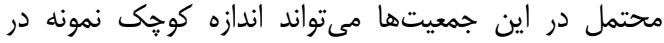

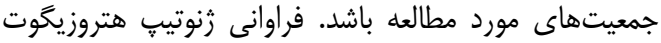

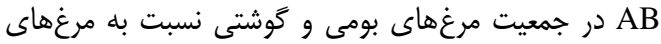

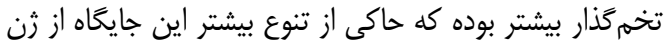
PEPCK-C

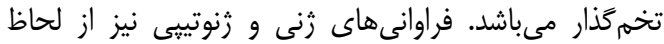

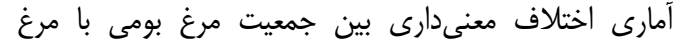

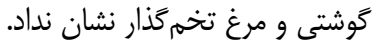

\section{M}

M

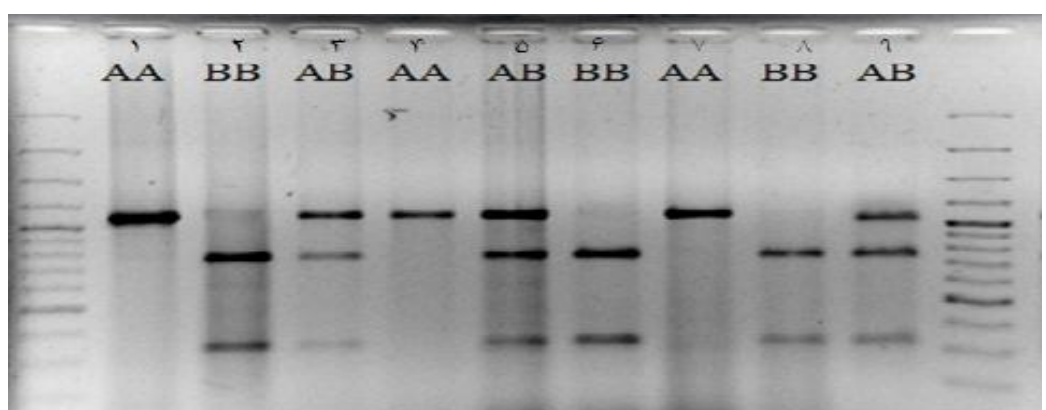

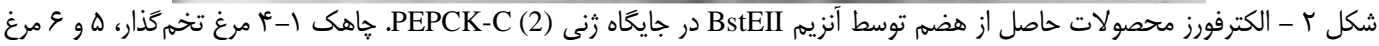

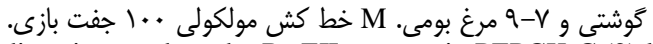

Figure 2. Electrophoresis of digestion products by BstEII enzyme in PEPCK-C (2) locus. Lane 1-4 layer, 5 and 6 broiler and 7-9 native fowls. $\mathrm{M}$ is the $100 \mathrm{bp}$ molecular ruler.

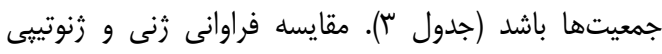

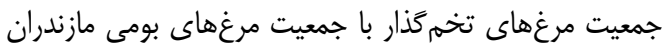

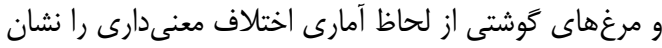

داد (P)

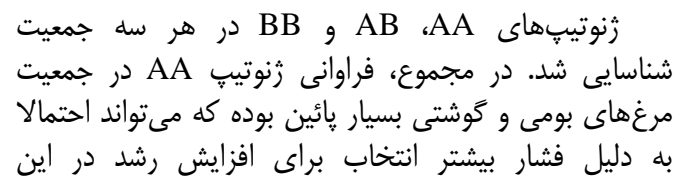

جدول سـ- فراوانى هاى آللى و زنوتييى ثن PEPCK-C (2) در سه سويه مختلف مرغ Table 3. The allelic and genotypic frequencies of PEPCK-C (2) in three different strains of chickens

\begin{tabular}{|c|c|c|c|c|c|c|c|c|}
\hline \multicolumn{4}{|c|}{ سطح احتمال(P- value) } & \multicolumn{2}{|c|}{ فراوانى آللى } & \multicolumn{2}{|c|}{ فراوانى زنوتيبى } & \multirow[b]{2}{*}{ جمعيت } \\
\hline مرغ تخمثذار & مرغ گوشتى & مرغ بومى & B & A & BB & $\mathrm{AB}$ & $\mathrm{AA}$ & \\
\hline$\cdot|+\cdot|^{* \pi}$ & $\cdot / \Lambda \wedge \& v^{n s}$ & ----- & $\cdot / V T$ & $\cdot / 4 \lambda$ &.$/ 48$ &.$/ \Delta T$ & $\cdot / \cdot r$ & مرغ بومى \\
\hline$\cdot 1+\left.\cdots\right|^{* * \pi}$ & ---- & $\cdot / \Lambda \& V^{\mathrm{ns}}$ & $\cdot|\wedge|$ &.$/ 19$ &.$/ 94$ & . & $.1 \cdot r$ & مرغ گُشتى \\
\hline ----- & $\cdot 1+\cdots 1^{* \pi}$ & $+1+\cdots 1^{* * \pi}$ &.$/ 41$ & .109 & . /MF & F & . Rt & مرغ تخم گذار \\
\hline
\end{tabular}

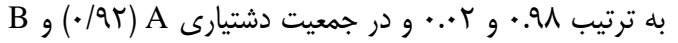

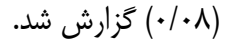
يارسانثاد و همكاران (ع) (1) با استفاده از تكنيك RFLP در

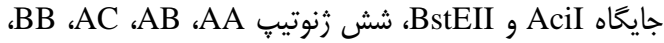

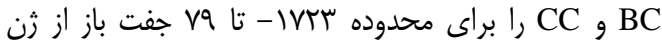
تخناسايى كردند كه زنوتيب AA PAPCK-C

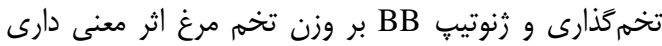

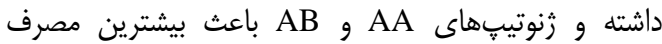
خوراك در طيور نزاد لخمهورن شدند.

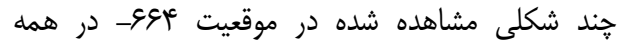

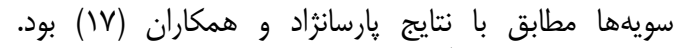

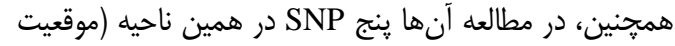

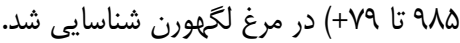

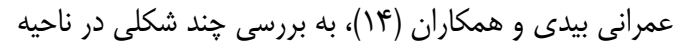

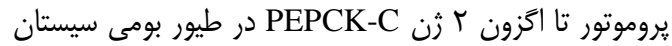

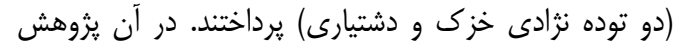

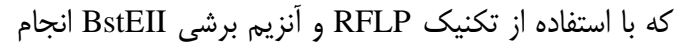

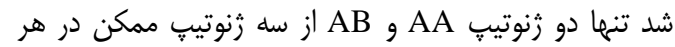
دو جمعيت مشاهده شد. فراوانى آلل A و A 
مطالعه شده نشان نداد. به عبارت ديخر اين جايگاه (موقعيت

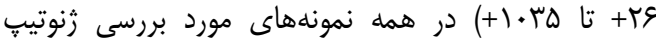

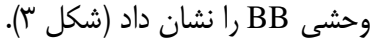

PEPCK-C (3) براى جايخًاه BstEII - RFLP

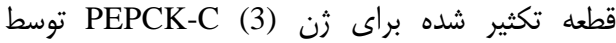

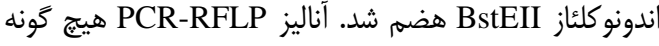
جند شكلى براى ثن PEPCK-C (3) در ميان سويههاى

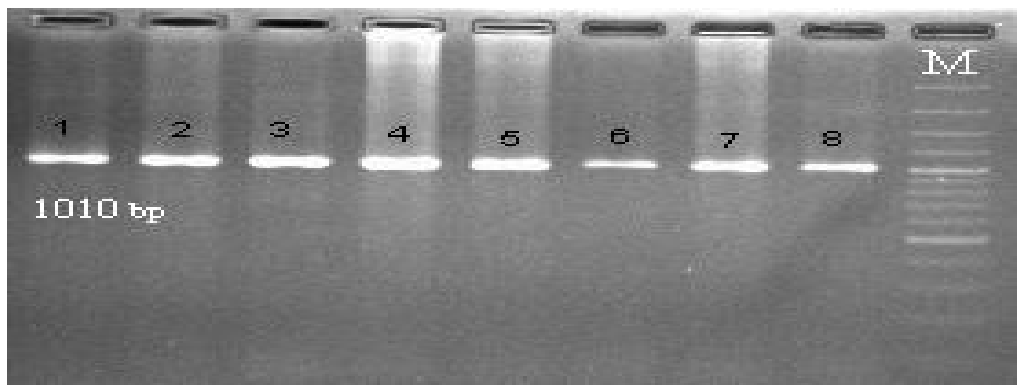

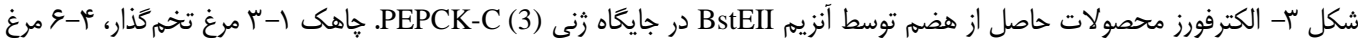

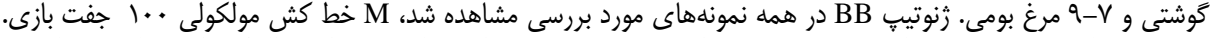

Figure 3. Electrophoresis of digestion products by BstEII enzyme in PEPCK-C (3) locus. Lane 1-3 layer, 4-6 broiler and 7-8 native fowls. BB genotype observed in all samples. $\mathrm{M}$ is the 100bp molecular ruler

ممكن است به دليل شدت انتخاب به نفع اين زنوتيب و يا

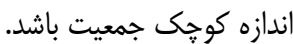

PEPCK-C (4) براى جايخًاه PstI -RFLP

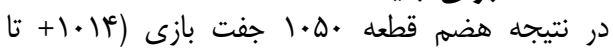

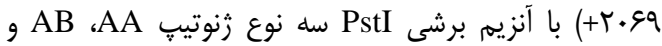

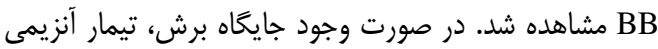

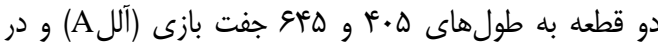

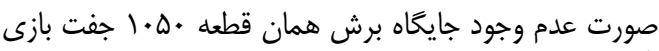
(آلل B ايجاد نمود (شكل عاء).

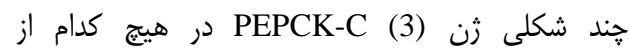

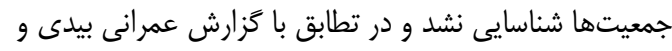

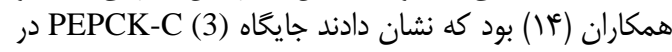

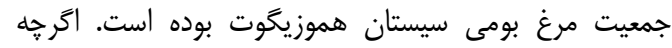

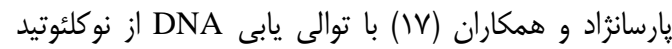

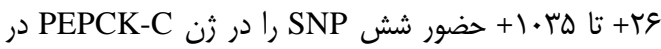

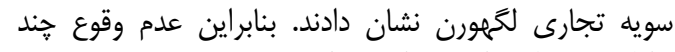

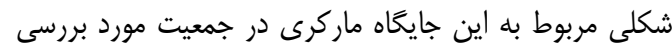

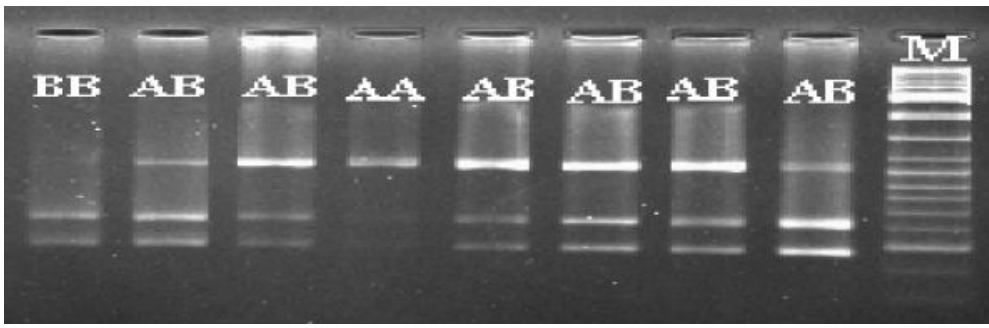

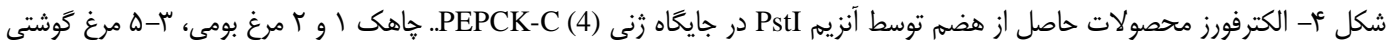

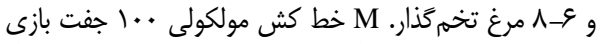

Figure 4. Electrophoresis of digestion products by PstI enzyme in PEPCK-C (4) locus. Lane 1 and 2 native fowls, 3-5 broiler and 6-8 layer. $\mathrm{M}$ is the 100bp molecular ruler

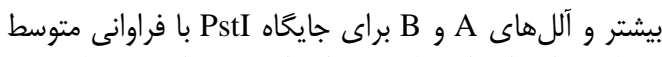

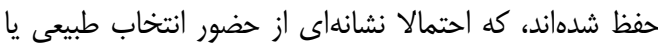

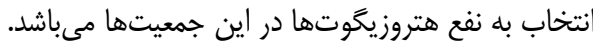

توزيع فراوانى آللى و زنوتيبى حاصل از تيمار آنزيم PstI

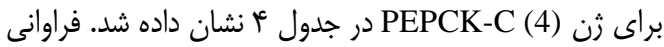

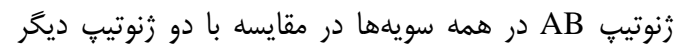

جدول عأ- فراوانى هاى آللى و زنوتيبى ثن (4) PEPCK-C در سه سويه مختلف مرغ Table 4. The allelic and genotypic frequencies of PEPCK-C (4) in three different strains of chickens

\begin{tabular}{|c|c|c|c|c|c|c|c|c|}
\hline \multicolumn{3}{|c|}{ سطح احتمال (P- value) } & \multicolumn{2}{|c|}{ فراوانى آللى } & \multicolumn{3}{|c|}{ فراوانى زنوتيبى } & \multirow[b]{2}{*}{ جمعيت } \\
\hline مرغ تخهم كذار & مرغ كوشتى & مرغ بومى م & B & A & BB & $\mathrm{AB}$ & AA & \\
\hline$\cdot 1 \cdots \Lambda^{*}$ & $\cdot / / Q \mid V^{\mathrm{nS}}$ & ----- & $\cdot / \Delta V$ & Tאוא. &.$/ \cdot r$ &.$/ \Delta F$ &.$/ 19$ & مرغ بومى \\
\hline $.1 \cdot \Delta T \Lambda^{\circ}$ & ----- & - $/ \Lambda \Delta I V^{\mathrm{ns}}$ & $\cdot / 4 \lambda$ & $\cdot / \Delta T$ &.$/ 14$ &. $\mid 91$ &.$/ 1 \Lambda$ & مرغ كوشتى \\
\hline----- & . $\cdot$ DTA & $\cdot \cdots \Lambda^{N \cdots}$ & $\cdot / \Delta$ & $\cdot / 0$ & .1 .9 & $\cdot / M$ & .1 .9 & مرغ تخمثذار \\
\hline
\end{tabular}




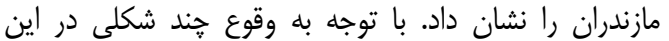

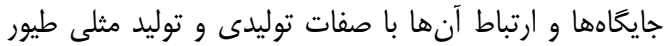

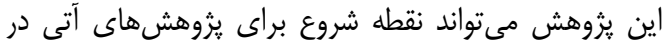

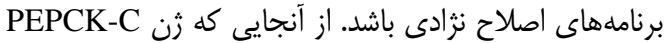

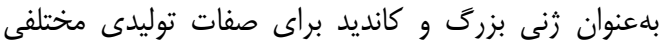

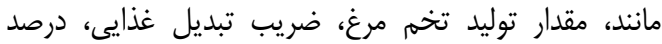

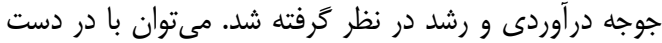

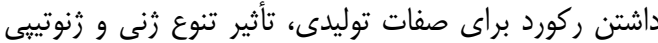

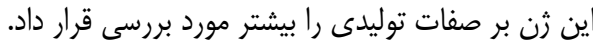

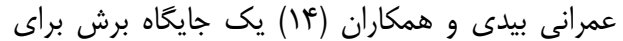

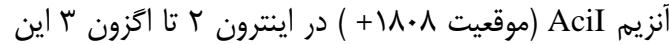

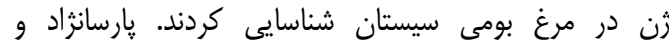

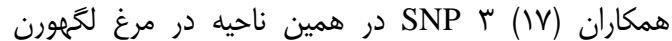

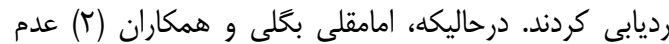

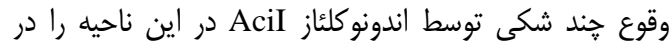

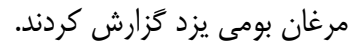

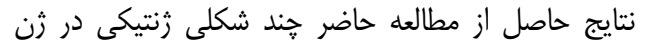

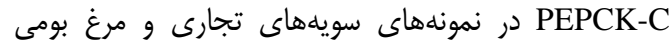

1. Cook, J.S., S.L. Weldon, J.P. Garcia-Ruiz and Y. Hod. 1986. Nucleotide sequence of the mRNA encoding the cytosolic form of phosphoenolpyruvate carboxykinase (GTP) from the chicken. National Academy of Science, 83: 7583-7587.

2. Emamgholi Begli, H., S. Zerehdaran, S. Hassani, M. Ali Abbasi and A.R. Khan Ahmadi. 2010. Polymorphism in prolactin and PEPCK-C genes and its association with economic traits in native fowl of Yazd province. Iranian Journal of Biotechnology, 8: 172-177.

3. Garaber, A.J., F.J. Ballard and R.W. Hanson. 1972. In metabolism and the regulation of metabolic processes in mitochondria (Mehlman M.A. and R.W. Hanson, eds) Academic press. New York, 109-135.

4. Hanson, R. and L. Reshef. 1997. Regulation of phosphoenolpyruvate carboxykinase (GTP) gene expression. Annual Review. Journal of Biochemistry, 66: 581-611.

5. Hers, H.G. and L. Hue. 1983. Gluconeogenesis and related aspects of glycolysis. Annual Review. Journal of Biochemistry, 52: 617-53.

6. Hod, Y., J.S. Cook, S.L. Weldon, J.M. Short, A. Wynshaw-Boris and R.W. Hanson. 1986. Differential expression of the genes for the mitochondrial and cytosolic forms of phosphoenolpyruvate carboxykinase. Annual. New York. Academic. Science, 478: 31-45.

7. Hod, Y., M.F. Utter and R.W. Hanson. 1982. The mitochondrial and cytosolic forms of avian phosphoenolpyruvate are encoded by different messenger RNA . Journal of Biological Chemistry, 257: $13787-13794$.

8. Krebs, H.A. 1972. Essays. Biochem, 8: 1-34.

9. Krebs, H.A. and H.L. Kornberg. 1957. Energy transformations in living matter: a survey. Springer- verlag press, Berlin and Heidelberg GmbH Co. KG, Germany, 273 pp.

10. Lamers, W., R.W. Hanson and H. Meisner. 1982. cAMP stimulates transcription of the gene for the gene for cytosolic Phosphoenolpyruvate carboxykinase in rat liver nuclei. Proceeding of National Academy of Science U.S.A, 79(17): 5137-5141.

11. Miller, S.A., D.D. Dykesand and H.F. Polesky.1988.A simple salting out procedure for extracting DNA from human nucleated cells. Nucleic Acids Research, 16: 1215.

12. Nelson, D.L. and M.M. Cox. 2009. Lehninger, Principles of Biochemistry. $5^{\text {rd }}$ edn, 1100 pp.

13. Nordlie, R.C. and H.A. Lardy. 1963. Mammalian liver phosphoenolpyruvate carboxykinase activities. Journal of Biological Chemistry, 238: 2259-2265.

14. OmraniBidi, J., M. Alipanah, A. Torkamanzehi, S.A. Hoseini and M.R. Nasiri. 2011. Polymorphism in the PEPCK-C gene of sistan and baluchestan native chicken breeds. Genetics-novin, 4: 39-46 (In Persian).

15. Panserat, S., E. Plagnes-Yuan, J. Breaue and S. KAushik. 2001. Hepatic phosphoenolpyruvate carboxykinase gene expression is not repressed by dietary carbohydrates in rainbow trout. The Journal of Experimental Biology, 204: 359-365.

16. Parsanejad, R., A. Torkamanzehi, D. Zadworny and U. Kuhnlein. 2003. Alleles of cytosolic Phosphoenolpyruvate carboxy-kinase: trait association and interaction with mitochondrial PEPCK in a strain of white leghorn chickens. Journal of Poultry Science, 82: 1708 -1715.

17. Parsanejad, R., D. Zadworny and U. Kuhnlein. 2002. Genetic variability of the cytosolic Phosphoenolpyruvate carboxy-kinase gene in White Leghorn chickens. Journal of Poultry Science, 81: 1668-1670.

18. Sato, A., H. Takahashi, K. Konishi, T. Suzuki and H. Kochi. 1997. Nucleotide sequence of the promoter region of chicken cytosolic phosphoenol- pyruvate carboxykinase gene. Journal of Biochemistry, 121: 711716.

19. Savon, S., P. Hakimi and R.W. Hanson. 1993. Expression of the genes for the mitochondrial and cytosolic forms of phosphoenolpyruvate carboxykinase in avian liver during development. Journal of Biological Neonate, 64(1): 62-68.

20. Shrago, E., H.A. Lardy, R.C. Nordlie and D.O. Foster. 1963. Metabolic and Hormonal Control of Phosphoenolpyruvate Carboxykinase and Malic Enzyme in Rat liver. Journal of Biological Chemistry, 238(10): 3188-3192.

21. Soling, H.D. and J. Kleineke. 1976. In Gluconeogenesis: Its regulation in mammalian species (R.W. Hanson and M.A. Mehlman, Eds.). wiiey, New York, pp: 369-462.

22. Utter, M.F. and K. Kurahashi. 1954. Purification of Oxalacetic Carboxylase from Chicken Liver. Journal of Biological Chemistry, 207: 787-802.

23. Watford, M., Y. Hod, Y.B. Chiao, M.F. Uttert and R.W. Hanson. 1981. The unique role of the kidney in gluconeogenesis in the chicken. Journal of Biological Chemistry, 256: 10023-10027.

24. Weldon, S.L., A. Rendo, A.S. Mathias, Y. Hod P.A. kalonick, S. Sanon and R.W. Hanson. 1990. Mitochondrial phosphoenolpyruvate carboxykinase form the chicken: comparison of the cDNA and protein sequences whit the cytosolic isozyme. Journal of Biological Chemistry, 265: 7308-7317. 


\title{
Analysis of Genetic Polymorphisms in Four Marker Sites of PEPCK-C Gene in Different Strains of Chickens
}

\author{
Zohreh Yousefi ${ }^{1}$, Ghodrat Rahimi Mianjii ${ }^{2}$ and Zarbakht Ansari Pirsaraei ${ }^{3}$ \\ 1- M.Sc. Student Department of Animal Science, Sari Agricultural Sciences and Natural Resources University \\ (Corresponding author: yosefi_2004@yahoo.com) \\ 2 and 3- Professor and Associate Professor Department of Animal Science, Sari Agricultural Sciences and Natural \\ Resources University \\ Received: July 2, $2015 \quad$ Accepted: October 21, 2015
}

\begin{abstract}
This research was carried out in order to detect the polymorphisms in four sites of PEPCK-C gene by PCR-RFLP method in a commercial layer and broiler strains and breeder hens of Mazandaran native fowls breeding station. Blood samples were collected randomly from 150 birds from a three populations and DNA was extracted using modified salting out method. Using polymerase chain reaction (PCR) and specific primers pairs a region with the length of 3792 bp from position -1723 to exon 4 from PEPCK-C gene was amplified. In RsaI marker site two alleles of A $(33 \%)$ and B $(67 \%)$ were detected in Mazandaran native fowls, A (34\%), B $(66 \%)$ in commercial broiler and A $(24 \%)$ and B $(76 \%)$ in commercial layer population. Two genotypes of $\mathrm{AB}$ and $\mathrm{BB}$ were detected with the frequency of 66 and 34\% in Mazandaran native fowls 68 and $32 \%$ in commercial broiler and 48 and $52 \%$ in commercial layer hens. In BstEII marker site two alleles of A $(28 \%)$ and B $(72 \%)$ were detected in Mazandaran native fowls population, A (19\%), B (81\%) in commercial broiler and A $(59 \%)$ and B $(41 \%)$ in commercial layer lines. Three genotypes of $\mathrm{AA}, \mathrm{AB}$ and $\mathrm{BB}$ were detected with the frequency of 2,52 and 46 in Mazandaran native fowls, 2, 34 and 64\% in commercial broiler and 42, 34 and $24 \%$ commercial layer. In PstI marker site two alleles of A $(43 \%)$ and B $(57 \%)$ were detected in Mazandaran native fowls population, A $(52 \%)$, B (48\%) in commercial broiler and A and B $(50 \%)$ in commercial layer samples. Three genotypes of AA, AB and BB were detected with the frequency of 16, 54 and $30 \%$ in Mazandaran native fowls, 18, 68 and $14 \%$ in commercial broiler and 6, 88 and $6 \%$ in commercial layer population. In BstEII marker site (position +26 to $+1035)$ the results showed that all samples from different strains had the same banding pattern with monomorphic BB genotype. Among 3 observed SNPs 2 were in the promoter site and 1 in intron 2 region. As a result of finding polymorphism in this marker site and also its major effect on production traits such as egg for production, feed conversion ratio and growth rate it can be considered as a candidate gene in detection of QTL related to these traits in poultry industry.
\end{abstract}

Keywords: Polymorphism, PEPCK-C, Chicken, PCR-RFLP 